\title{
Anesthetic-sensitive ion channel modulation is associated with a molar water solubility cut-off
}

\author{
Robert J. Brosnan * (D) and Trung L. Pham
}

\begin{abstract}
Background: NMDA receptor modulation by hydrocarbons is associated with a molar water solubility cut-off. Low-affinity phenolic modulation of $\mathrm{GABA}_{\mathrm{A}}$ receptors is also associated with a cut-off, but at much lower molar solubility values. We hypothesized that other anesthetic-sensitive ion channels exhibit distinct cut-off effects associated with hydrocarbon molar water solubility, and that cut-off values are comparatively similar between related receptors than phylogenetically distant ones.

Methods: Glycine or $\mathrm{GABA}_{\mathrm{A}}$ receptors or TREK-1, TRESK, $\mathrm{Na}_{\mathrm{V}} 1.2$, or $\mathrm{Na}_{\mathrm{V}} 1.4$ channels were expressed separately in frog oocytes. Two electrode voltage clamp techniques were used to study current responses in the presence and absence of hydrocarbon series from eight functional groups with progressively increasing size at saturated aqueous concentrations. Null response (cut-off) was defined by current measurements that were statistically indistinguishable between baseline and hydrocarbon exposure.

Results: Ion channels exhibited cut-off effects associated with hydrocarbon molar water solubility in the following order of decreasing solubility: $\mathrm{Na}_{v} 1.2 \approx \mathrm{Na}_{\mathrm{v}} 1.4 \geq \mathrm{TRESK} \approx \mathrm{TREK}-1>\mathrm{GABA}_{\mathrm{A}}>>$ glycine. Previously measured solubility cut-off values for NMDA receptors were intermediate between those for $\mathrm{Na}_{v} 1.4$ and TRESK.

Conclusions: Water solubility cut-off responses were present for all anesthetic-sensitive ion channels; distinct cut-off effects may exist for all cell surface receptors that are sensitive to volatile anesthetics. Suggested is the presence of amphipathic receptor sites normally occupied by water molecules that have dissociation constants inversely related to the cut-off solubility value. Poorly soluble hydrocarbons unable to reach concentrations sufficient to out-compete water for binding site access fail to modulate the receptor.
\end{abstract}

Keywords: Anesthesia, Mechanism, Ion channel, Electrophysiology, Aliphatic

\section{Background}

Protein-ligand interactions are commonly described using a "lock-and-key" model in which the protein and ligand have to fit together to have a chemical effect [1]. Although inhaled anesthetics are presumed to exert their effects through ion channels and cell surface receptor proteins, the diverse nature of both anesthetic ligands and the proteins they modulate challenge assumptions of a conserved complementary structure $[2,3]$. Current and historical inhaled anesthetics include single atoms, triatomic molecules, various alkanes (with and without halogens), various

* Correspondence: rjbrosnan@ucdavis.edu

Department of Surgical and Radiological Sciences, School of Veterinary

Medicine, University of California, One Shields Avenue, Davis, CA 95616, USA ethers (with and without halogens), and various alkenes (with and without halogens); experimental inhaled anesthetics demonstrate even greater structural variety. Hence, these drugs act as structurally diverse keys that each can open the same lock. Moreover, a single inhaled anesthetic can allosterically modulate function of a large number of structurally diverse and phylogenetically unrelated ion channels-including many different ligand-gated ion channels, voltage-gated ion channels, and leak channelsand cell surface receptors-including many different channel-linked receptors, enzyme-linked receptors, and $\mathrm{G}$ protein-coupled receptors. Hence, these agents also act like a key that can open many different locks.

(C) The Author(s). 2018 Open Access This article is distributed under the terms of the Creative Commons Attribution 4.0 International License (http://creativecommons.org/licenses/by/4.0/), which permits unrestricted use, distribution, and reproduction in any medium, provided you give appropriate credit to the original author(s) and the source, provide a link to the Creative Commons license, and indicate if changes were made. The Creative Commons Public Domain Dedication waiver (http://creativecommons.org/publicdomain/zero/1.0/) applies to the data made available in this article, unless otherwise stated. 
Inhaled anesthetics typically have high median effective concentrations consistent with low-affinity target interactions [4], and these agents can bind multiple amphipathic sites on a protein of which at least some may be associated with water molecules [5]. Anesthetic modulation of protein function firstly depends upon the presence of an agent in sufficient concentration to desolvate, displace weaklybound water molecules within an allosteric binding site, and only then bind to the allosteric site. We postulate that drugs with insufficient water solubility to competitively displace water from this amphipathic allosteric site would be unable to bind and modulate the protein-a cut-off effect-even at a saturated aqueous phase drug concentration. These low-affinity amphipathic drug-receptor interactions could be associated with different hydrocarbon solubility cut-off values for different proteins since the water dissociation constants within critical allosteric sites could also be different for different proteins. In support, $\mathrm{N}$-methyl-d-aspartate (NMDA) receptor whole-cell currents are unchanged by saturated concentrations of organic compounds once the hydrocarbon $\omega$-end or ring size is increased such that the predicted molar water solubility is less than approximately $1.1 \mathrm{mM}$; yet these same hydrocarbons still are able to allosterically modulate $\gamma$-aminobutyric acid receptor type A $\left(\mathrm{GABA}_{\mathrm{A}}\right)$ currents [6]. However, $\mathrm{GABA}_{\mathrm{A}}$ receptors may have their own hydrocarbon cut-off, as $\mathrm{GABA}_{\mathrm{A}}$ receptor whole-cell currents are unchanged by a series of substituted phenol and benzene rings once the predicted molar water solubility of these compounds is less than $0.1 \mathrm{mM}$ [7].

We hypothesize that cut-off effects associated with molar water solubility is a generalizable feature of inhaled anesthetic-sensitive ion channels and receptors. As a test, we evaluated responses of anesthetic-sensitive channels and receptors to eight different functional groups of organic compounds, differing only by carbon additions to the $\omega$-end of a chain or to a ring, so that we could study compounds of different molecular volumes and carbon atoms but similar molar water solubility values (and vice versa) and therefore distinguish between effects caused by drug size versus solubility. Although inhaled anesthetics bind many different proteins, we studied six channels and receptors reported to contribute to immobilizing effects in vivo: voltage-gated sodium channels type II and type IV $\left(\mathrm{Na}_{\mathrm{v}} 1.2\right.$ and $\left.\mathrm{Na}_{\mathrm{v}} 1.4\right)$, [8] TWIK-related spinal cord channel (TRESK) [9], TWIK-related potassium channel type I (TREK-1) [10], GABA A receptors [11], and glycine receptors [12].

\section{Methods}

\section{Oocyte collection}

Adult female Xenopus laevis vivarium-maintained frogs (Xenopus Express, Brooksville, FL) were anesthetized with chilled $0.2 \%$ buffered tricaine, surgically ovariectomized, and were either administered morphine analgesia and recovered from anesthesia (first ovariectomy) or euthanized (second ovariectomy) by decapitation and double pithing while anesthetized. The theca externa and mesovarium of the removed ovary were disrupted manually, and oocytes were defolliculated enzymatically by use of $0.2 \%$ collagenase. Oocytes were stored in a modified Barth's electrolyte solution until ready for use. This protocol was approved by the Institutional Animal Care and Use Committee at the University of California, Davis.

\section{Receptor expression}

Each anesthetic-sensitive receptor type was separately expressed in different oocytes by injecting plasmids containing sequences for receptor subunits which were provided as gifts from the laboratory of R. Adron Harris (University of Texas, Austin). All plasmids were sequenced and their identity confirmed by comparison to National Center for Biotechnology Information databases. Human voltage-gated Type II sodium channels $\left(\mathrm{Na}_{\mathrm{v}} 1.2\right)$ were expressed by intracytoplasmic injection of $5 \mathrm{ng}$ RNA per oocyte containing the SCN2A gene; human voltage gated Type IV sodium channels $\left(\mathrm{Na}_{\mathrm{v}} 1.4\right)$ were similarly expressed using RNA encoding the SCN4A gene. The human TRESK channel $\left(\mathrm{K}_{2 \mathrm{P}} 18.1\right)$ was expressed by intracytoplasmic injection of 5 ng RNA per oocyte containing the KCNK18 gene; the human TREK-1 channel $\left(\mathrm{K}_{2 \mathrm{P}} 2.1\right)$, was similarly expressed using RNA encoding the KCNK2 gene. Heterotrimeric $\mathrm{GABA}_{\mathrm{A}}$ receptors were expressed by a $1 \mathrm{ng}$ oocyte intranuclear co-injection of three different plasmids containing cytomegalovirus promoters and coding DNA for one of thee subunits-human $\alpha_{1}$ (GABRA1), rat $\beta_{2}$ (GABRB2), or rat $\gamma_{2 \mathrm{~s}}$ (GABRG2 short)-in a 1:1:10 ratio to ensure incorporation of the $\gamma$-subunit; this was confirmed by demonstrating receptor potentiation to $10 \mu \mathrm{M}$ chlordiazepoxide during co-application with GABA. Glycine receptors were expressed by intracytoplasmic injection of $5 \mathrm{ng}$ RNA per oocyte containing the gene for the human glycine $\alpha_{1}$ subunit (GLRA1). Nucleasefree water-injected oocytes served as negative controls for all experiments.

\section{Electrophysiology studies}

Oocytes were incubated at $18{ }^{\circ} \mathrm{C}$ for $1-4$ days in fresh and filtered modified Barth's solution composed of $88 \mathrm{mM}$ $\mathrm{NaCl}, 1 \mathrm{mM} \mathrm{KCl}, 2.4 \mathrm{mM} \mathrm{NaHCO} 3,20 \mathrm{mM}$ HEPES, $0.82 \mathrm{mM} \mathrm{MgSO}_{4}, 0.33 \mathrm{mM} \mathrm{Ca}\left(\mathrm{NO}_{3}\right)_{2}, 0.41 \mathrm{mM} \mathrm{CaCl} \mathrm{C}_{2}$, $5 \mathrm{mM}$ sodium pyruvate, gentamycin, penicillin, streptomycin, and corrected to $\mathrm{pH}=7.4$. All salts and antibiotics were A.C.S. grade (Fisher Scientific, Pittsburgh, PA). Oocytes were studied in a $250 \mu \mathrm{L}$ linear-flow chamber perfused with frog Ringer's (FR) solution composed of $115 \mathrm{mM} \mathrm{NaCl}, 2.5 \mathrm{mM} \mathrm{KCl}, 1.8 \mathrm{mM} \mathrm{CaCl}_{2}$, and $10 \mathrm{mM}$ HEPES prepared in 18.2 $\mathrm{M} \Omega \mathrm{H} 2 \mathrm{O}$ and filtered and 
adjusted to $\mathrm{pH}=7.4$. All solutions were delivered to the perfusion chamber via a syringe pump with gastight glass syringes and foil-wrapped Teflon tubing.at a rate of $1.5 \mathrm{ml} / \mathrm{min}$. Oocytes were impaled by two $3 \mathrm{M} \mathrm{KCl-filled}$ 0.2-1 M $\Omega$ borosilicate glass electrodes (KG-33, King Precision Glass, Claremont, CA) connected to separate headstages (Axon Instruments HS2A, Molecular Devices, San Jose, CA) through which voltage was measured and current was passed by use of a computer-controlled amplifier (Axon Instruments GeneClamp 500B, Molecular Devices, San Jose, CA) [6].

For oocytes expressing $\mathrm{Na}_{\mathrm{v}}$ channels, the cell transmembrane potential was clamped at $-80 \mathrm{mV}$ with a $200 \mathrm{~ms}$ step increase to $0 \mathrm{mV}$ applied approximately every minute. The $\mathrm{Na}_{\mathrm{v}}$ channel response was calculated as the difference between the current required to maintain the holding potential and the largest negative current deflection produced by the voltage step. For oocytes expressing $K_{2 \mathrm{P}}$ channels, the transmembrane potential was clamped at $-60 \mathrm{mV}$, and voltage was stepped to $+60 \mathrm{mV}$ each minute. The $K_{2 \mathrm{P}}$ channel response was calculated as the difference between holding potential current and voltage step plateau current. For both channel types, baseline responses were measured during oocyte perfusion with FR for a minimum of three times to demonstrate response variability $<10 \%$. The perfusate was then switched to the hydrocarbon test drug dissolved at a saturated aqueous phase concentration in FR for 2 min after which the current response to the step voltage was measured. The hydrocarbon drug was then washed out for 5-10 min, and the current response was again measured to demonstrate that it was within $10 \%$ of the initial baseline response.

For two-electrode voltage clamp studies in oocytes expressing $\mathrm{GABA}_{\mathrm{A}}$ receptors or glycine receptors, the transmembrane potential was clamped at $-80 \mathrm{mV}$ while being perfused with FR. Approximately every $5 \mathrm{~min}$, the perfusate was switched for $30 \mathrm{~s}$ to $\mathrm{FR}+\mathrm{EC}_{10}$ agonist$20 \mu \mathrm{M}$ 4-aminobutanoic acid for $\mathrm{GABA}_{\mathrm{A}}$ receptors or $40 \mu \mathrm{M}$ aminoethanoic acid for glycine receptors-and then the perfusate was switched back to FR for agonist washout. The current response for each ligand-gated ion channel was calculated as the difference between the peak current measured in the presence of agonist and the whole-cell current measured immediately prior to agonist exposure. Baseline responses were measured in triplicate to confirm $<10 \%$ variability of current responses in the absence of drug exposure. Next, the perfusate was switched to the hydrocarbon test drug dissolved at a saturated aqueous phase concentration for $2 \mathrm{~min}$ followed by a 30s exposure the same concentration of hydrocarbon dissolved in FR + agonist. The hydrocarbon drug was then washed out, and oocytes were exposed to FR + agonist 5 and $10 \mathrm{~min}$ later to verify return of the current response to within $10 \%$ of pre-drug baseline levels.

\section{Drug solution preparation}

Using predicted density values published in SciFinder (Chemical Abstracts Service, American Chemical Society, Columbus $\mathrm{OH}$ ), drug solutions were prepared by anaerobic addition of a hydrocarbon volume to gastight glass syringes containing either FR or FR + agonist to create a concentration equal to its calculated molar water solubility (Table 1). After vigorous agitation, an immiscible hydrocarbon microbubble could be found in the syringe, confirming that a saturated solution had been achieved. However, butane is a gas a room temperature and pressure, and a saturated aqueous phase cannot be achieved because butane vapor pressure exceeds atmospheric pressure. Instead, using FR or FR + agonist containing 1 atm $\mathrm{O}_{2}$ partial pressure in gastight glass syringes, butane drug solutions were prepared by repeated syringe headspace exchanges to yield solutions with gas partial pressures that were $90 \%$ butane and $10 \% \mathrm{O}_{2}$.

\section{Data analysis}

Drug responses were calculated as a percent change from the control (baseline) current responses as follows: \%change $=\frac{I_{D}-I_{B}}{I_{B}}$, where $\mathrm{I}_{\mathrm{D}}$ and $\mathrm{I}_{\mathrm{B}}$ are the current responses measured during perfusions with drug and without drug (baseline), respectively. Average current responses for each drug and channel were described by mean \pm SEM. A positive current change indicated drug-induced positive allosteric modulation of the channel, whereas a negative current change indicated negative allosteric modulation (inhibition) of channel function. A drug-receptor cut-off response was defined as an absolute value change in current $<10 \%$ from baseline that was statistically indistinguishable from zero using a two-tailed Student $\mathrm{t}$-test. The $\log _{10}$ of the calculated solubility $\left(\log _{10} S\right)$ for compounds immediately below and above the cut-off for each hydrocarbon functional group were used to determine the receptor cut-off. For each hydrocarbon, there was a "grey area" of indeterminate solubility effect between sequentially increasing hydrocarbon chain lengths. Mean solubility cut-offs were calculated as the average $\log _{10} \mathrm{~S}$ for the least soluble compound that modulated receptor function and the most soluble neighboring compound for which no effect was observed. From this result, a 95\% confidence interval for $\log _{10} \mathrm{~S}$ was calculated for receptor solubility cut-offs.

\section{Results}

Sample channel recordings are shown in Fig. 1, and hydrocarbon effects on each anesthetic-sensitive ion channel are summarized in Table 2 . With increasing carbon additions to the $\omega$-end or ring, all anesthetic-sensitive channels exhibited a cut-off effect, defined by $<10 \%$ channel modulation, the smallest effect size that is reliably resolved 
Table 1 Source, purity and physical properties of study compounds

\begin{tabular}{|c|c|c|c|c|c|c|c|c|}
\hline Compound & CAS\# & MW (amu) & $P_{\text {vap }}(m m H g)$ & Solubility (M) & Carbon (\#) & Volume $\left(\AA^{3}\right)$ & Source & Purity (\%) \\
\hline \multicolumn{9}{|l|}{ Alcohols } \\
\hline 1-octanol & $111-87-5$ & 130.23 & $1.14 \times 10^{-1}$ & $9.0 \times 10^{-3}$ & 8 & 262 & Alfa Aesar & $>99$ \\
\hline 1-nonanol & $143-08-8$ & 144.25 & $4.07 \times 10^{-2}$ & $2.7 \times 10^{-3}$ & 9 & 290 & Alfa Aesar & $>99$ \\
\hline 1-decanol & $112-30-1$ & 158.28 & $1.48 \times 10^{-2}$ & $6.5 \times 10^{-4}$ & 10 & 317 & Aldrich & $>99$ \\
\hline 1-undecanol & $112-42-5$ & 172.31 & $5.10 \times 10^{-3}$ & $1.7 \times 10^{-4}$ & 11 & 344 & Acros & 98 \\
\hline 1-dodecanol & $112-53-8$ & 186.33 & $2.09 \times 10^{-3}$ & $4.1 \times 10^{-5}$ & 12 & 372 & $\mathrm{TCl}$ & 99 \\
\hline 1-tridecanol & $112-70-9$ & 200.36 & $8.07 \times 10^{-4}$ & $1.2 \times 10^{-5}$ & 13 & 400 & Aldrich & 97 \\
\hline 1-tetradecanol & $112-72-1$ & 214.39 & $1.47 \times 10^{-4}$ & $2.1 \times 10^{-6}$ & 14 & 427 & Fluka & $>99$ \\
\hline 1-pentadecanol & $629-76-5$ & 228.41 & $1.27 \times 10^{-4}$ & $4.7 \times 10^{-7}$ & 15 & 454 & Aldrich & 99 \\
\hline \multicolumn{9}{|l|}{ Aldehydes } \\
\hline nonanal & $124-19-6$ & 142.24 & $5.32 \times 10^{-1}$ & $2.3 \times 10^{-3}$ & 9 & 289 & Aldrich & 95 \\
\hline decanal & $112-31-2$ & 156.27 & $2.07 \times 10^{-1}$ & $9.8 \times 10^{-4}$ & 10 & 316 & Aldrich & 98 \\
\hline undecanal & $112-44-7$ & 170.29 & $8.32 \times 10^{-2}$ & $4.2 \times 10^{-4}$ & 11 & 344 & Aldrich & 97 \\
\hline dodecanal & $112-54-9$ & 184.32 & $3.44 \times 10^{-2}$ & $1.8 \times 10^{-4}$ & 12 & 372 & $\mathrm{TCl}$ & 98 \\
\hline tridecanal & $10486-19-8$ & 198.34 & $1.46 \times 10^{-2}$ & $8.2 \times 10^{-5}$ & 13 & 399 & $\mathrm{TCl}$ & 98 \\
\hline tetradecanal & $124-25-4$ & 212.37 & $6.39 \times 10^{-3}$ & $3.7 \times 10^{-5}$ & 14 & 427 & $\mathrm{TCl}$ & 98 \\
\hline heptadecanal & $629-90-3$ & 254.45 & $6.22 \times 10^{-4}$ & $3.5 \times 10^{-6}$ & 17 & 509 & $\mathrm{TCl}$ & $>97$ \\
\hline octadecanal & $638-66-4$ & 268.48 & $3.00 \times 10^{-4}$ & $1.7 \times 10^{-6}$ & 18 & 536 & $\mathrm{TCl}$ & $>95$ \\
\hline docosanal & $57402-36-5$ & 324.58 & $2.02 \times 10^{-5}$ & $9.1 \times 10^{-8}$ & 20 & 646 & Alfa Aesar & 98 \\
\hline \multicolumn{9}{|l|}{ Alkanes } \\
\hline butane & $106-97-8$ & 58.12 & $1.92 \times 10^{3}$ & $1.4 \times 10^{-3}$ & 4 & 156 & Matheson & 99.99 \\
\hline pentane & $109-66-0$ & 72.15 & $5.27 \times 10^{2}$ & $4.3 \times 10^{-4}$ & 5 & 184 & Aldrich & $>99$ \\
\hline hexane & $110-54-3$ & 86.18 & $1.51 \times 10^{2}$ & $1.2 \times 10^{-4}$ & 6 & 211 & Acros & $>99$ \\
\hline heptane & $142-82-5$ & 100.20 & $4.52 \times 10^{1}$ & $3.1 \times 10^{-5}$ & 7 & 239 & Acros & $>99$ \\
\hline octane & $111-65-9$ & 114.23 & $1.42 \times 10^{1}$ & $6.9 \times 10^{-6}$ & 8 & 267 & Acros & $>99$ \\
\hline nonane & $111-84-2$ & 128.26 & $4.63 \times 10^{0}$ & $1.4 \times 10^{-6}$ & 9 & 294 & Acros & 99 \\
\hline decane & $124-18-5$ & 142.28 & $1.58 \times 10^{0}$ & $2.6 \times 10^{-7}$ & 10 & 321 & Acros & $>99$ \\
\hline undecane & $1120-21-4$ & 156.31 & $5.64 \times 10^{-1}$ & $4.2 \times 10^{-8}$ & 11 & 349 & Acros & 99 \\
\hline tetradecane & $629-59-4$ & 198.39 & $2.85 \times 10^{-2}$ & $6.1 \times 10^{-9}$ & 14 & 431 & Aldrich & $>99$ \\
\hline eicosane & $112-95-8$ & 282.55 & $1.40 \times 10^{-4}$ & $2.9 \times 10^{-9}$ & 20 & 596 & Aldrich & 99 \\
\hline \multicolumn{9}{|l|}{ Alkenes } \\
\hline 1-pentene & $109-67-1$ & 70.13 & $6.37 \times 10^{2}$ & $1.4 \times 10^{-3}$ & 5 & 176 & Aldrich & 99 \\
\hline 1-hexene & $592-41-6$ & 84.16 & $1.88 \times 10^{2}$ & $4.2 \times 10^{-4}$ & 6 & 203 & Aldrich & $>99$ \\
\hline 1-octene & $111-66-0$ & 112.21 & $1.79 \times 10^{1}$ & $2.6 \times 10^{-5}$ & 8 & 258 & Aldrich & 98 \\
\hline 1-nonene & $124-11-8$ & 126.24 & $5.77 \times 10^{0}$ & $7.4 \times 10^{-6}$ & 9 & 286 & Aldrich & 96 \\
\hline 1-decene & $872-05-9$ & 140.27 & $1.92 \times 10^{0}$ & $1.5 \times 10^{-6}$ & 10 & 313 & Aldrich & $>97$ \\
\hline 1-undecene & $821-95-4$ & 154.29 & $6.61 \times 10^{-1}$ & $2.6 \times 10^{-7}$ & 11 & 341 & Aldrich & 97 \\
\hline 1-dodecene & $112-41-4$ & 168.32 & $2.34 \times 10^{-1}$ & $4.1 \times 10^{-8}$ & 12 & 368 & Aldrich & $>99$ \\
\hline 1-tridecene & 2437-56-1 & 182.35 & $8.5610^{-2}$ & $5.8 \times 10^{-9}$ & 13 & 396 & Aldrich & 96 \\
\hline \multicolumn{9}{|l|}{ Alkynes } \\
\hline 1-hexyne & $693-02-7$ & 82.14 & $1.35 \times 10^{2}$ & $2.9 \times 10^{-3}$ & 6 & 184 & Aldrich & 97 \\
\hline 1-heptyne & 628-71-7 & 96.17 & $4.35 \times 10^{1}$ & $6.6 \times 10^{-4}$ & 7 & 212 & Acros & 99 \\
\hline 1-octyne & $629-05-0$ & 110.2 & $1.44 \times 10^{1}$ & $1.9 \times 10^{-4}$ & 8 & 239 & Acros & 99 \\
\hline 1-nonyne & $3452-09-3$ & 124.22 & $4.87 \times 10^{0}$ & $3.9 \times 10^{-5}$ & 9 & 267 & Aldrich & 99 \\
\hline
\end{tabular}


Table 1 Source, purity and physical properties of study compounds (Continued)

\begin{tabular}{|c|c|c|c|c|c|c|c|c|}
\hline Compound & CAS\# & MW (amu) & $P_{\text {vap }}(\mathrm{mmHg})$ & Solubility (M) & Carbon (\#) & Volume $\left(\AA^{3}\right)$ & Source & Purity (\%) \\
\hline 1-decyne & $764-93-2$ & 138.25 & $1.69 \times 10^{0}$ & $7.9 \times 10^{-6}$ & 10 & 294 & Aldrich & 98 \\
\hline 1-undecyne & $2243-98-3$ & 152.28 & $6.05 \times 10^{-1}$ & $1.4 \times 10^{-6}$ & 11 & 322 & $\mathrm{TCl}$ & 98 \\
\hline 1-dodecyne & $765-03-7$ & 166.30 & $2.22 \times 10^{-1}$ & $2.4 \times 10^{-7}$ & 12 & 349 & $\mathrm{TCl}$ & 98 \\
\hline \multicolumn{9}{|l|}{ Amines } \\
\hline 1-octadecanamine & $124-30-1$ & 269.51 & $4.88 \times 10^{-5}$ & $1.3 \times 10^{-3}$ & 18 & 546 & $\mathrm{TCl}$ & 97 \\
\hline 1-eicosanamine & $10525-37-8$ & 297.56 & $8.96 \times 10^{-6}$ & $2.7 \times 10^{-4}$ & 20 & 601 & Rambus & 95 \\
\hline 1-hexacosanamine & $14130-10-0$ & 381.72 & $8.91 \times 10^{-8}$ & $2.3 \times 10^{-5}$ & 26 & 766 & ACC & 98 \\
\hline 1-octacosanamine & $14130-12-2$ & 409.77 & $2.21 \times 10^{-8}$ & $6.3 \times 10^{-6}$ & 28 & 821 & $\mathrm{ACC}$ & 98 \\
\hline 1-triacontanamine & $66214-00-4$ & 437.83 & $5.85 \times 10^{-9}$ & $1.8 \times 10^{-6}$ & 30 & 876 & ACC & 98 \\
\hline \multicolumn{9}{|l|}{ Cycloalkanes } \\
\hline cyclopentane & $287-92-3$ & 70.13 & $3.14 \times 10^{2}$ & $3.3 \times 10^{-3}$ & 5 & 147 & Aldrich & $>99$ \\
\hline cyclohexane & $110-82-7$ & 84.16 & $9.37 \times 10^{1}$ & $1.0 \times 10^{-3}$ & 6 & 176 & Aldrich & $>99.7$ \\
\hline cycloheptane & $291-64-5$ & 98.19 & $1.99 \times 10^{1}$ & $2.9 \times 10^{-4}$ & 7 & 206 & Aldrich & 96 \\
\hline cyclooctane & $292-64-8$ & 112.21 & $4.56 \times 10^{0}$ & $7.2 \times 10^{-5}$ & 8 & 236 & Aldrich & $>99$ \\
\hline cyclodecane & 293-96-9 & 140.27 & $4.47 \times 10^{-1}$ & $3.2 \times 10^{-6}$ & 10 & 295 & Aldrich & 95 \\
\hline cycloundecane & 294-41-7 & 154.29 & $1.85 \times 10^{-1}$ & $5.7 \times 10^{-7}$ & 11 & 324 & Aldrich & 95 \\
\hline cyclododecane & $294-62-2$ & 168.32 & $4.13 \times 10^{-2}$ & $9.2 \times 10^{-8}$ & 12 & 353 & $\mathrm{TCl}$ & $>99$ \\
\hline \multicolumn{9}{|l|}{ Ethers } \\
\hline dibutyl ether & $142-96-1$ & 130.23 & $7.10 \times 10^{0}$ & $1.6 \times 10^{-2}$ & 8 & 277 & Aldrich & 99.3 \\
\hline dipentyl ether & $693-65-2$ & 158.28 & $1.00 \times 10^{0}$ & $3.0 \times 10^{-3}$ & 10 & 331 & Fluka & $>98.5$ \\
\hline dihexyl ether & $112-58-3$ & 186.33 & $1.48 \times 10^{-1}$ & $5.8 \times 10^{-4}$ & 12 & 386 & Aldrich & 97 \\
\hline diheptyl ether & $629-64-1$ & 214.39 & $2.23 \times 10^{-2}$ & $1.2 \times 10^{-4}$ & 14 & 442 & $\mathrm{TCl}$ & 98 \\
\hline dioctyl ether & $629-82-3$ & 242.44 & $4.53 \times 10^{-3}$ & $2.4 \times 10^{-5}$ & 16 & 497 & $\mathrm{TCl}$ & 98 \\
\hline didecyl ether & $2456-28-2$ & 298.55 & $8.08 \times 10^{-5}$ & $1.2 \times 10^{-6}$ & 20 & 606 & $\mathrm{TCl}$ & 98 \\
\hline diundecyl ether & $43146-97-0$ & 326.60 & $1.24 \times 10^{-5}$ & $2.3 \times 10^{-7}$ & 22 & 661 & $\mathrm{TCl}$ & 98 \\
\hline
\end{tabular}

CAS\# Chemical Abstracts Service number, $M W$ molecular weight, $P_{\text {vap }}$ vapor pressure at $25^{\circ} \mathrm{C}$, molar solubility in pure water at pH $=7$, and molecular volume are calculated estimates (rather than measured values) referenced by SciFinder Scholar

given the given baseline variability allowed in these studies. All current modulation above this value was statistically different from baseline.

The mean hydrocarbon molar water solubility cut-off value and 95\% confidence interval range for each ion channel is as follows (Fig. 2): $\mathrm{Na}_{\mathrm{v}} 1.2=1.4 \mathrm{mM}(0.81 \mathrm{mM}-$ $2.4 \mathrm{mM}) ; \quad \mathrm{Na}_{\mathrm{v}} 1.4=1.2 \mathrm{mM} \quad(0.62 \mathrm{mM}-2.3 \mathrm{mM})$; TRESK $=0.59 \mathrm{mM} \quad(0.26 \mathrm{mM}-1.3 \mathrm{mM})$; TREK $-1=$ $0.51 \mathrm{mM}(0.24 \mathrm{mM}-1.1 \mathrm{mM}) ; \mathrm{GABA}_{\mathrm{A}}=120 \mu \mathrm{M}(60 \mu \mathrm{M}-$ $250 \mu \mathrm{M})$; Glycine $=0.63 \mu \mathrm{M}(0.24 \mu \mathrm{M}-1.7 \mu \mathrm{M})$. Loss of ion channel modulation generally occurred in this same order for all organic compounds, with some clustering of cut-offs for the $\mathrm{Na}_{\mathrm{v}}$ and $\mathrm{K}_{2 \mathrm{P}}$ at similar molar water solubility values.

For each ion channel, the calculated molar water solubility was the only physical-chemical property examined that was associated with similar cut-off values between different hydrocarbon functional groups. An example of this is shown in Fig. 3 in which the grey indeterminate bars that separate known regions of positive and absent modulation are clustered around a relatively narrow molar water solubility cut-off range. Other channels, when similarly graphed as a function of hydrocarbon molar water solubility, show qualitatively similar results but with clustering around each channel's own distinct molar water solubility cut-off value. In contrast, $\mathrm{GABA}_{\mathrm{A}}$ receptor cut-off effects are not associated with the number of molecular carbon atoms or molecular volume of the hydrocarbon (Fig. 4), and these results mirror those of the other anesthetic-sensitive ion channels studied here.

Both $\mathrm{Na}_{\mathrm{v}}$ channels were inhibited by all of the hydrocarbons tested above their respective cut-off values, whereas both of the ligand-gated ion channels $\left(\mathrm{GABA}_{\mathrm{A}}\right.$ and glycine receptors) were potentiated by all compounds above their respective cut-off values (Table 2). However, the $K_{2 \mathrm{P}}$ channels were differently affected by compounds with different organic functional groups. Both were positively modulated by alkanes, alkenes, alkynes, cycloalkanes, and ethers, and both were negatively modulated by aldehydes and primary amines. However, whereas primary 

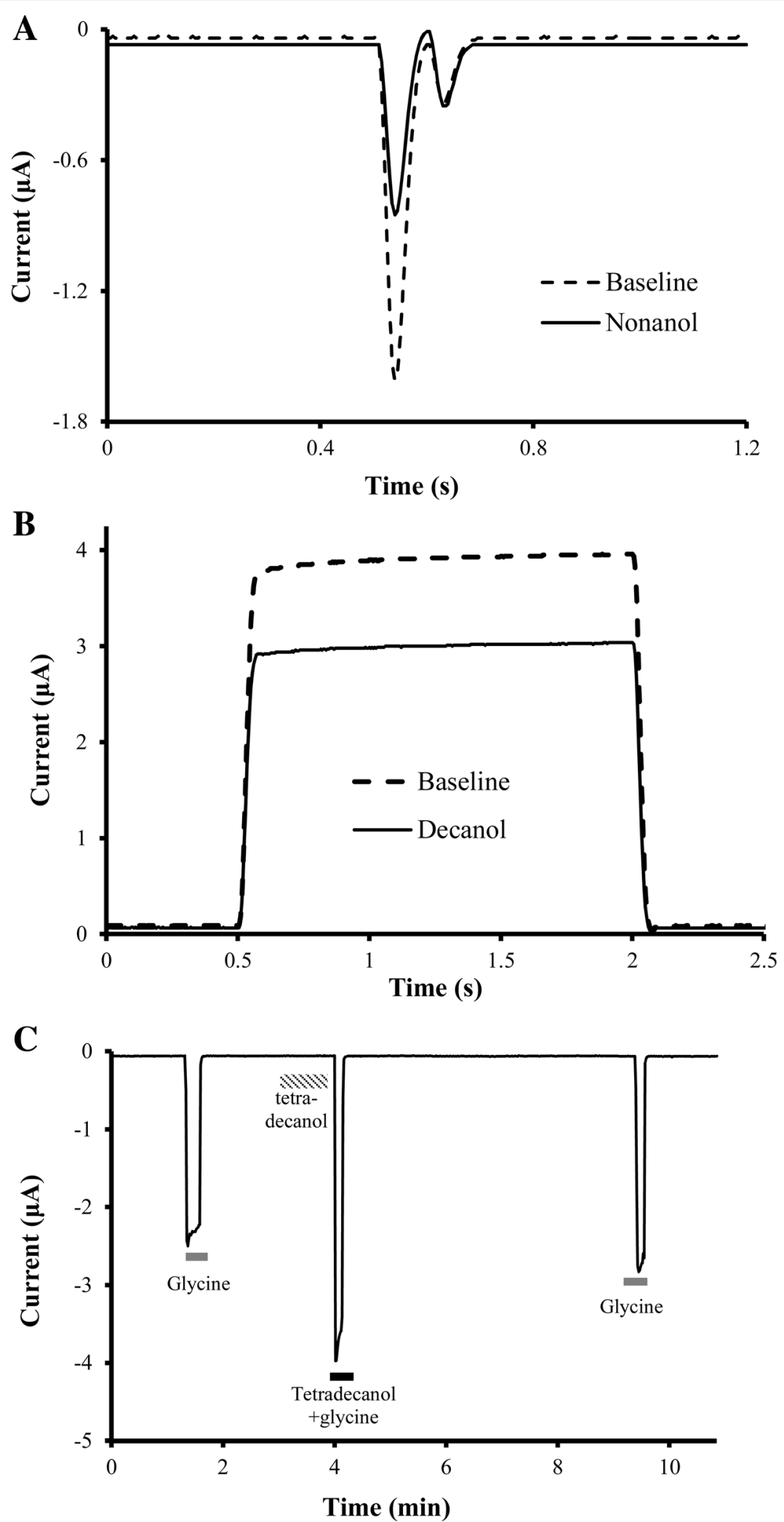

Fig. 1 Sample tracings for (a) Nav1.2 channels, (b) TREK-1 channels, and (c) glycine receptors before and after alcohol exposure at saturated aqueous phase concentrations (Table 1). Whole cell current responses were qualitatively similar between both $\mathrm{Na}_{\vee}$ channels and between both $\mathrm{K}_{2 \mathrm{P}}$ channels. Electrophysiologic responses of $\mathrm{GABA}_{\mathrm{A}}$ receptors during similar hydrocarbon exposure studies have been published elsewhere [6, 7] 
Table 2 Percent change \pm SEM of whole-cell currents measured during two-electrode voltage clamp studies in response to administration of saturated concentration of each hydrocarbon (or $90 \% \mathrm{~atm}$ for butane)

\begin{tabular}{|c|c|c|c|c|c|c|}
\hline Compound & $\mathrm{Na}_{\mathrm{v}} 1.2$ & $\mathrm{Na}_{\mathrm{v}} 1.4$ & TRESK & TREK-1 & $\mathrm{GABA}_{\mathrm{A}}$ & Glycine \\
\hline \multicolumn{7}{|l|}{ Alcohols } \\
\hline 1-octanol & & & $74 \pm 5(5)^{*}$ & & & \\
\hline 1-nonanol & $-62 \pm 7(5)^{*}$ & $-48 \pm 4(6)^{*}$ & $41 \pm 4(5)^{*}$ & $-36 \pm 2(6)^{*}$ & & \\
\hline 1-decanol & $-4 \pm 1(5)$ & $-35 \pm 6(6)^{*}$ & $2 \pm 1(6)$ & $-28 \pm 4(6)^{*}$ & $322 \pm 29(5)^{*}$ & \\
\hline 1-undecanol & $-2 \pm 1(5)$ & $-4 \pm 1(5)$ & & $0 \pm 2(5)$ & $81 \pm 13(5)^{*}$ & \\
\hline 1-dodecanol & & & & & $39 \pm 6(7)^{*}$ & \\
\hline 1-tridecanol & & & & & $2 \pm 1(6)$ & \\
\hline 1-tetradecanol & & & & $5 \pm 3(5)$ & $4 \pm 2(5)$ & $38 \pm 6(6)^{*}$ \\
\hline 1-pentadecanol & & & & & & $-7 \pm 2(5)$ \\
\hline \multicolumn{7}{|l|}{ Aldehydes } \\
\hline nonanal & $-51 \pm 1(6)^{*}$ & & $-22 \pm 6(5)^{*}$ & & $119 \pm 29(7)^{*}$ & \\
\hline decanal & $-24 \pm 3(5)^{*}$ & $-31 \pm 3(6)^{*}$ & $-4 \pm 2(5)$ & $-45 \pm 3(5)^{*}$ & & \\
\hline undecanal & $-6 \pm 1(5)$ & $-2 \pm 1(5)$ & & $-20 \pm 2(6)^{*}$ & & \\
\hline dodecanal & & & & $-5 \pm 1(5)$ & & \\
\hline tridecanal & & & & & $20 \pm 3(7)^{*}$ & \\
\hline tetradecanal & & & & & $5 \pm 2(9)$ & \\
\hline heptadecanal & & & & & & $31 \pm 2(5)^{*}$ \\
\hline octadecanal & & & & & & $20 \pm 3(5)^{*}$ \\
\hline docosanal & & & & & & $1 \pm 2(7)$ \\
\hline \multicolumn{7}{|l|}{ Alkanes } \\
\hline butane & $-20 \pm 2(7)^{*}$ & $-22 \pm 2(5)^{*}$ & $25 \pm 5(6)^{*}$ & $61 \pm 9(5)^{*}$ & $523 \pm 68(5)^{*}$ & \\
\hline pentane & $-1 \pm 1(5)$ & $-2 \pm 1(5)$ & $7 \pm 1(5)$ & $-3 \pm 2(5)$ & $221 \pm 10(7)^{*}$ & \\
\hline hexane & & $-1 \pm 0(2)$ & & $4 \pm 3(4)$ & $29 \pm 5(6)^{*}$ & $61 \pm 5(5)^{*}$ \\
\hline heptane & & $0 \pm 1(5)$ & & & $-3 \pm 1(5)$ & \\
\hline octane & & & & & $-1 \pm 4(2)$ & $206 \pm 21(5)^{*}$ \\
\hline nonane & & & & & & $62 \pm 18(5)^{*}$ \\
\hline decane & & & & & $5 \pm 2(2)$ & $20 \pm 3(6)^{*}$ \\
\hline undecane & & & & & & $8 \pm 2(5)$ \\
\hline tetradecane & & & & & & $5 \pm 1(5)$ \\
\hline eicosane & & & & & & $9 \pm 4(2)$ \\
\hline \multicolumn{7}{|l|}{ Alkenes } \\
\hline 1-pentene & $-28 \pm 2(5)^{*}$ & $-45 \pm 4(5)^{*}$ & & & $351 \pm 38(6)^{*}$ & \\
\hline 1-hexene & $1 \pm 1(5)$ & $0 \pm 0(6)$ & $37 \pm 7(5)^{*}$ & $157 \pm 13(5)^{*}$ & $83 \pm 8(6)^{*}$ & \\
\hline 1-octene & & & $2 \pm 1(5)$ & $1 \pm 1(5)$ & $7 \pm 3(5)$ & \\
\hline 1-nonene & & & & & $7 \pm 4(6)$ & \\
\hline \multicolumn{7}{|l|}{ 1-decene } \\
\hline 1-undecene & & & & & & $54 \pm 7(5)^{*}$ \\
\hline 1-dodecene & & & & & & $-3 \pm 3(5)^{*}$ \\
\hline 1-tridecene & & & & & & $1 \pm 1(5)$ \\
\hline \multicolumn{7}{|l|}{ Alkynes } \\
\hline 1-hexyne & $-44 \pm 2(5)^{*}$ & $-34 \pm 2(5)^{*}$ & $44 \pm 5(5)^{*}$ & & $313 \pm 23(6)^{*}$ & \\
\hline 1-heptyne & $-2 \pm 4(5)$ & $-4 \pm 2(6)$ & $29 \pm 5(7)^{*}$ & $55 \pm 5(4)^{*}$ & $78 \pm 5(7)^{*}$ & \\
\hline 1-octyne & & $2 \pm 1(5)$ & $5 \pm 2(5)$ & $-1 \pm 2(9)$ & $-3 \pm 1(6)$ & \\
\hline
\end{tabular}


Table 2 Percent change \pm SEM of whole-cell currents measured during two-electrode voltage clamp studies in response to administration of saturated concentration of each hydrocarbon (or $90 \%$ atm for butane) (Continued)

\begin{tabular}{|c|c|c|c|c|c|c|}
\hline Compound & $\mathrm{Na}_{\mathrm{v}} 1.2$ & $\mathrm{Na}_{\mathrm{v}} 1.4$ & TRESK & TREK-1 & $\mathrm{GABA}_{\mathrm{A}}$ & Glycine \\
\hline 1-nonyne & & & & & $6 \pm 1(4)$ & \\
\hline 1-decyne & & & & & $7 \pm 1(6)$ & $55 \pm 14(5)^{*}$ \\
\hline 1-undecyne & & & & & & $223 \pm 20(6)^{*}$ \\
\hline 1-dodecyne & & & & & & $3 \pm 2(5)$ \\
\hline \multicolumn{7}{|l|}{ Amines } \\
\hline 1-octadecanamine & $-15 \pm 1(6)^{*}$ & $-11 \pm 1(6)^{*}$ & $-23 \pm 2(6)^{*}$ & $-16 \pm 1(5)^{*}$ & $46 \pm 5(8)^{*}$ & \\
\hline 1-eicosanamine & $0 \pm 0(6)$ & $-2 \pm 2(5)$ & $-1 \pm 1(7)$ & $-2 \pm 3(5)$ & $67 \pm 7(6)^{*}$ & \\
\hline 1-hexacosanamine & & & $0 \pm 2(6)$ & $-1 \pm 3(6)$ & $1 \pm 2(6)$ & \\
\hline 1-octacosanamine & & & & & & $26 \pm 3(7)^{*}$ \\
\hline 1-triacontanamine & & & & & & $2 \pm 1(6)$ \\
\hline \multicolumn{7}{|l|}{ Cycloalkanes } \\
\hline cyclopentane & $-45 \pm 4(5)^{*}$ & $-11 \pm 1(6)^{*}$ & $63 \pm 9(5)^{*}$ & $68 \pm 13(5)^{*}$ & $93 \pm 8(7)^{*}$ & \\
\hline cyclohexane & $-1 \pm 1(5)$ & $-2 \pm 2(5)$ & $1 \pm 1(6)$ & $63 \pm 6(6)^{*}$ & $321 \pm 17(5)^{*}$ & \\
\hline cycloheptane & $0 \pm 1(6)$ & & $0 \pm 1(5)$ & $-4 \pm 2(6)$ & $6 \pm 3(5)$ & \\
\hline \multicolumn{7}{|l|}{ cyclooctane } \\
\hline cyclodecane & & & & & & $22 \pm 3(5)^{*}$ \\
\hline cycloundecane & & & & & & $3 \pm 2(5)$ \\
\hline cyclododecane & & & & & & $0 \pm 1(5)$ \\
\hline \multicolumn{7}{|l|}{ Ethers } \\
\hline dibutyl ether & $-33 \pm 3(5)^{*}$ & $-44 \pm 5(5)^{*}$ & & $50 \pm 9(6)^{*}$ & $234 \pm 24(5)^{*}$ & \\
\hline dipentyl ether & $1 \pm 1(5)$ & $1 \pm 0(5)$ & $20 \pm 2(8)^{*}$ & $65 \pm 6(6)^{*}$ & $111 \pm 9(7)^{*}$ & \\
\hline dihexyl ether & & $0 \pm 1(5)$ & $2 \pm 1(6)$ & $3 \pm 2(6)$ & $13 \pm 1(5)^{*}$ & $143 \pm 10(5)^{*}$ \\
\hline diheptyl ether & & $-1 \pm 2(2)$ & & & $-1 \pm 4(5)$ & $74 \pm 8(6)^{*}$ \\
\hline dioctyl ether & & & & & $1 \pm 3(5)$ & $95 \pm 8(5)^{*}$ \\
\hline didecyl ether & & & & & & $28 \pm 4(6)^{*}$ \\
\hline diundecyl ether & & & & & & $2 \pm 2(7)$ \\
\hline
\end{tabular}

Positive changes indicate drug potentiation of channel function, and negative changes indicate drug inhibition of channel function. Drug-induced changes $\geq 10 \%$ in magnitude in either direction that are significantly greater than zero (not a cut-off response) are indicated by an asterisk. The number of oocytes studied for each channel and drug combination is shown in parentheses

alcohols potentiated TRESK currents, they inhibited TREK-1 currents.

As increasing hydrocarbon chain length decreased molar water solubility to values close to a channel cutoff value, there was commonly a decrease in the magnitude of current potentiation or inhibition (Table 2). Notable exceptions to this pattern are cyclohexane with $\mathrm{GABA}_{\mathrm{A}}$ receptors and undecyne with glycine receptors. Otherwise, there appeared no obvious relationship between hydrocarbon molar water solubility and either the magnitude or direction of receptor modulation.

\section{Discussion}

As shown previously for NMDA receptors, all of the anesthetic-sensitive ligand-gated, voltage-gated and leak channels examined in this study exhibited cut-off effects for each class of organic compounds, and these cut-offs were associated with the calculated molar water solubility of the hydrocarbon. The cut-offs occurred in a predictable order, with $\mathrm{Na}_{\mathrm{v}}$ channels $\mathrm{K}_{2 \mathrm{P}}$ channels, and $\mathrm{GABA}_{\mathrm{A}}$ receptors cut-offs all clustered within roughly one order magnitude of saturated drug concentrations. In contrast, the glycine receptor cut-off was associated with drug molar water solubility values over two orders of magnitude lower. If previously determined NMDA receptor results are included [6], cut-off responses proceed in order of decreasing hydrocarbon solubility as follows: $\mathrm{Na}_{\mathrm{v}} 1.2 \approx$ $\mathrm{Na}_{\mathrm{v}} 1.4 \gtrsim \mathrm{NMDA} \gtrsim \mathrm{TRESK} \approx \mathrm{TREK}-1>\mathrm{GABA}_{\mathrm{A}}>>$ glycine (Fig. 2).

Hydrocarbon cut-off responses in the present study, defined by $<10 \%$ effect, confirm data available in published literature. Horishita and Harris [13] found that the ability of primary alcohols to modulate $\mathrm{Na}_{\mathrm{v}} 1.2$ channels was lost between 1-octanol and 1-decanol, and is consistent with 


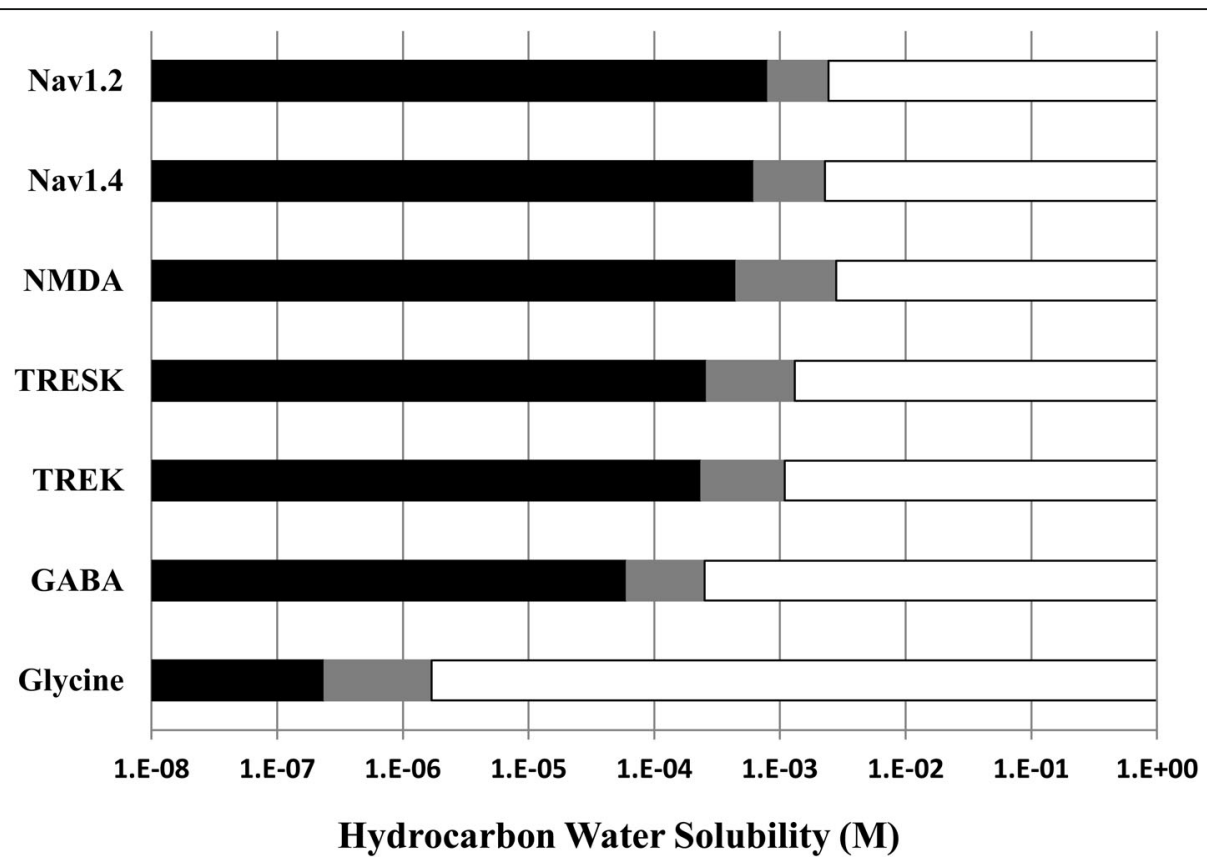

Fig. 2 Summary of ion channel response as a function of hydrocarbon molar water solubility. Hydrocarbons that modulate ion channel function are indicated by a white bar. Hydrocarbons that did not affect whole cell currents for an ion channel are indicated by a black bar. The grey bar represents the 95\% confidence interval around the mean hydrocarbon molar water solubility cut-off value for each ion channel

our finding of a cut-off between 1-nonanol and 1-decanol for this channel. Likewise, Peoples and Weight [14] observed $\mathrm{GABA}_{\mathrm{A}}$ receptor potentiation with primary alcohol chains up to 1-dodecanol and a cut-off effect at 1 -tridecanol and beyond, exactly where this cut-off was observed in the present study. The confidence interval for the $\mathrm{GABA}_{\mathrm{A}}$ receptor molar water solubility cut-off from this study also encompasses the calculated solubility cut-off values for substituted benzene and phenolic compounds [7].

Discrete water solubility-associated cut-off effects may be a common feature of all inhaled anesthetic-sensitive

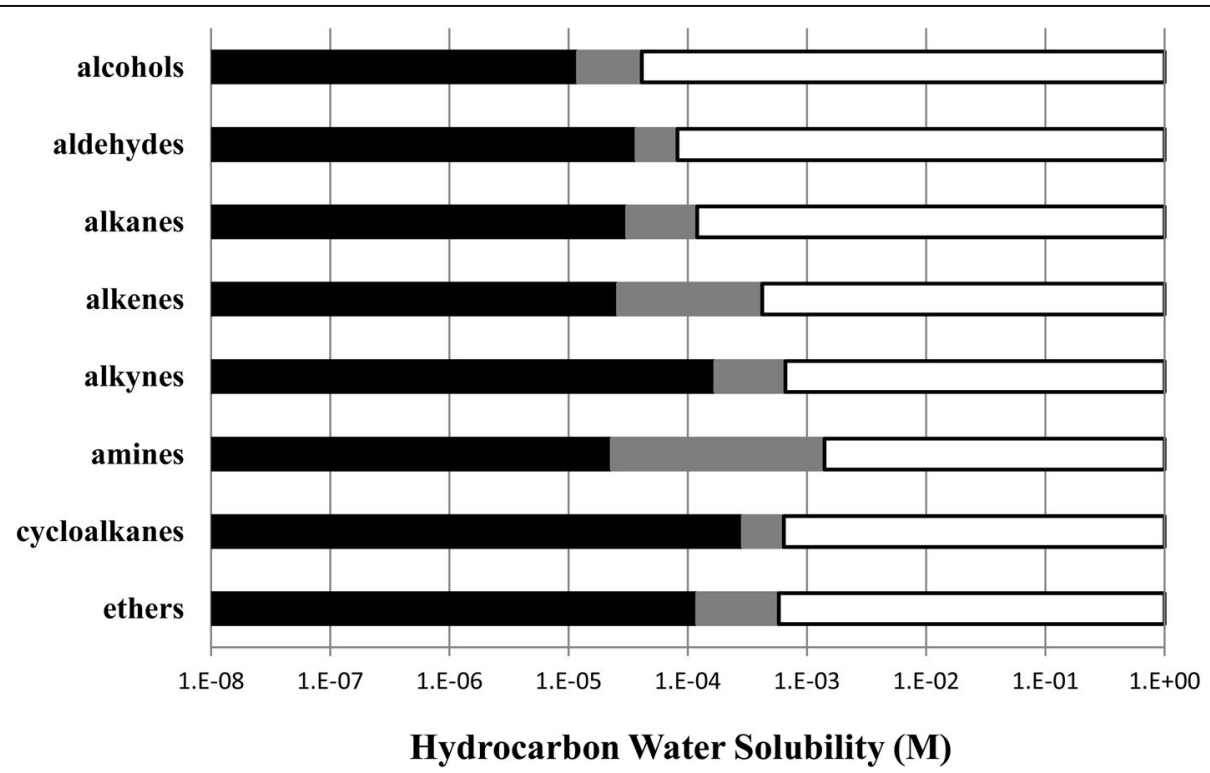

Fig. $3 \mathrm{GABA}_{\mathrm{A}}$ receptor current potentiation (white bars) and absent whole cell current effects for eight different organic classes graphed as a function of the calculated hydrocarbon molar water solubility. The grey bars represent hydrocarbon solubility ranges within each organic class for which $\mathrm{GABA}_{\mathrm{A}}$ receptor modulation was not evaluated. Cut-off values are clustered between $6.0 \times 10^{-5}$ and $2.5 \times 10^{-4} \mathrm{M}$ 

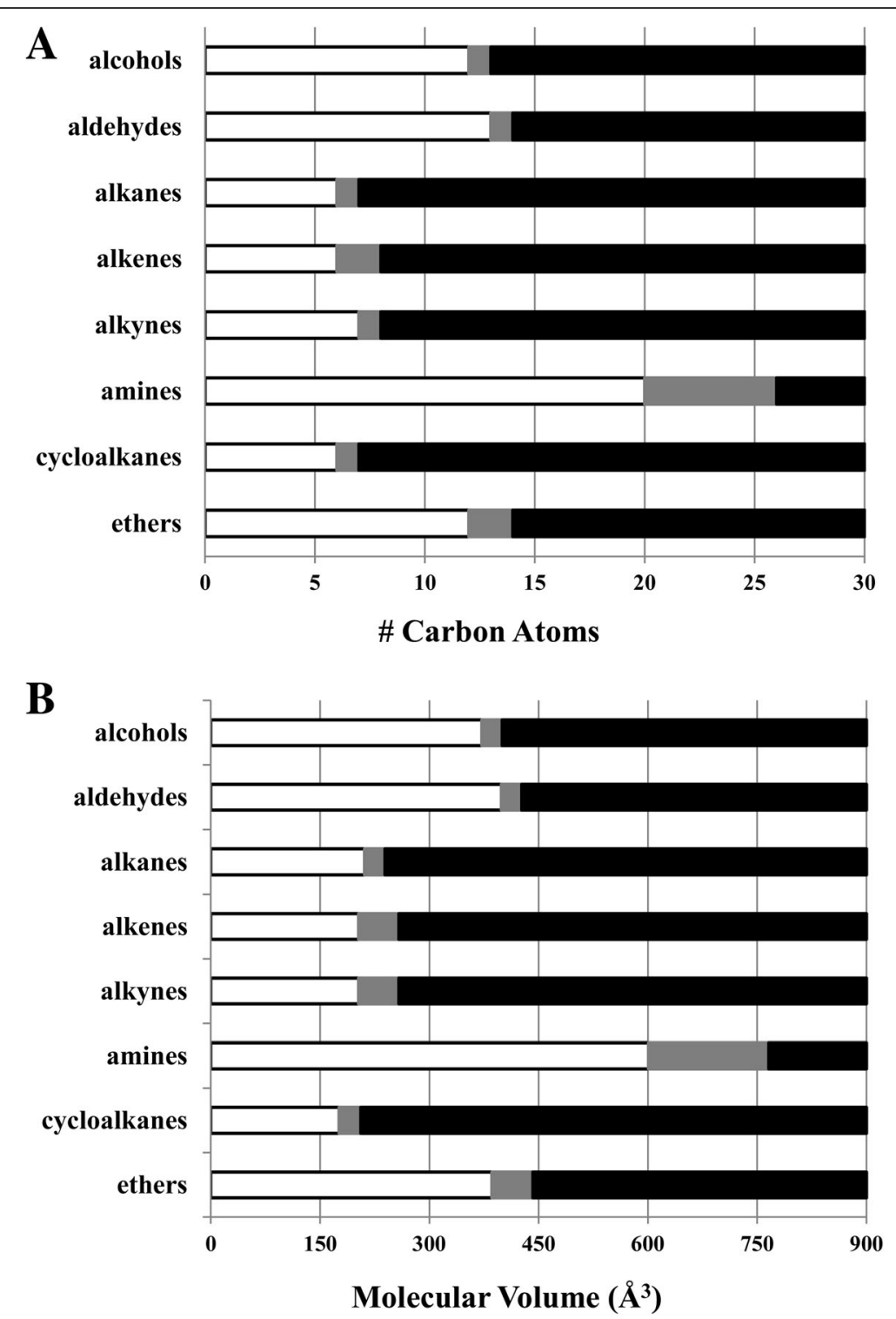

Fig. 4 Graph of $\mathrm{GABA}_{\mathrm{A}}$ receptor modulation as a function of the number of carbon atoms in a molecule (Panel a) and as a function of hydrocarbon molecular volume (Panel b). White and black bars indicate carbon numbers (Panel a) and molecular volumes (Panel b) associated with receptor potentiation and absent receptor modulation, respectively. Grey bars indicate regions for which hydrocarbon response data is not available. No pattern of consistent cut-off values associated with hydrocarbon chain length or molecular volume is evident

ion channels. Conventional volatile and gas anesthetics immobilize individuals at high aqueous phase concentrations [15] suggesting that they engage in low-affinity binding with target receptors. We postulate that these conventional anesthetic-receptor interactions mirror experimental hydrocarbon-receptor interactions, and we propose a molar water solubility hypothesis to describe non-specific drug binding to low-affinity and amphipathic allosteric sites on proteins. Before a ligand can alter protein function, it must first bind at a site capable of inducing a change in protein function. In order to bind, water molecules must be removed from the hydration shell surrounding the drug, and water molecules within the amphipathic protein pocket must be displaced. The ease with which the water is displaced from the protein pocket is described by its dissociation constant $\left(\mathrm{K}_{\mathrm{d}}\right)$. Water that is only weakly bound to amino acid side chains within the protein pocket would have a high $K_{d}$ and require fewer hydrocarbon molecules to successfully compete for access to this allosteric site. Consequently, this protein would have a lower molar water solubility cut-off. In contrast, water that is tightly bound within the pocket would have a low $K_{d}$, and therefore a high hydrocarbon concentration would be necessary to compete for access to this site. Such a protein would exhibit a high 
drug molar water solubility cut-off. It is possible that ion channels may have more than one amphipathic allosteric site for low-affinity interactions with inhaled anesthetics or other hydrocarbons [16-18]; however the methods employed in the present study would have identified receptor cut-off effects based only on the amphipathic allosteric site with the highest water $K_{d}$ in that receptor and which would therefore exhibit the lowest hydrocarbon molar water solubility cut-off effect among all modulatory sites. Other lower water $K_{d}$ sites could be important for binding and modulation by more soluble hydrocarbons and inhaled anesthetics when present at sufficient aqueous concentrations.

A second explanation for hydrocarbon molar water solubility cut-offs is possible. Desolvation of water molecules around the ligand is necessary for protein binding to occur. However, if the difference in free energy between the solvated protein-drug complex and the separated solvated protein and solvated drug is too great, then drug binding will be energetically unfavorable and no modulation of protein function will occur [19]. Larger hydrophobic drug ligands are surrounded by larger and more rigid water shells for which desolvation may be associated with greater enthalpy. The strength of water complexes around the ligand might increase to the point that drug receptor binding-and thus drug-receptor modulation can only occur if there remains sufficient entropy to overcome increased enthalpy of binding [20].

In either case, a molar water solubility hypothesis is not predicated on any particular molecular size, shape, polarity, functional groups, or atomic arrangement of the drug for low affinity interactions to take place. Indeed, the diversity of conventional anesthetics and other hydrocarbons capable of modulating a single anesthetic-sensitive ion channel, as well as the relatively minor effect differences produced by dug enantiomers [21], suggest that ligand structure itself is not crucial for binding. However, ligand structure does determine the magnitude and type of modulation for the protein it binds. Whether there is inhibition versus potentiation of $\mathrm{K}_{2 \mathrm{P}}$ channel currents, for example, will depend on the functional group of the hydrocarbon ligand (Table 2). Modulation magnitude also differed between functional groups; inhibition of $\mathrm{Na}_{\mathrm{v}} 1.4$ channels was approximately four times greater for alcohols, alkenes, and ethers than for amines or cycloalkanes. The importance of structural elements within receptor binding pockets has also been demonstrated through mutation studies that confer resistance to conventional anesthetic or other hydrocarbon modulation [22-24], although it is unknown whether some of these changes may also have altered the water $K_{d}$ or drug desolvation enthalpy that, in turn, could have affected the ability of the drug to bind the allosteric pocket.

The hydrocarbon molar water solubility cut-off value for each channel is expressed as confidence intervals, and certain error is inherent in their measurement. Butane, the smallest $\mathrm{n}$-alkane studied here, is a gas at room temperature and pressure, and therefore cannot be studied at a saturated aqueous phase concentration under normobaric conditions unlike the other liquid and solid hydrocarbons. All receptors were nonetheless modulated by $90 \%$ atm of butane, but had current modulation not been observed, a true cut-off could have been inferred at this submaximal concentration. Furthermore, carbon additions to the $\omega$-end of the hydrocarbon chain produce discrete, non-continuous changes in molar water solubility. For each series of functional groups, there is a range of solubility values that lie between the $C_{N}$ modulating hydrocarbon and the $\mathrm{C}_{\mathrm{N}+1}$ cut-off hydrocarbon where the receptor effect is unknown. Most important, however, is the reliance on calculated solubility values for hydrocarbons in pure water at $25{ }^{\circ} \mathrm{C}$ and $\mathrm{pH}=7.0$ rather than measured solubility values under study conditions with a $250 \mathrm{mOsm}$ electrolyte solution at $22{ }^{\circ} \mathrm{C}$ and $\mathrm{pH}=7.4$. Both accurate measurement and accurate prediction of solubility values are challenging for extremely hydrophobic compounds or for large or complex molecules with multiple functional groups. To limit this problem, only simple aliphatic compounds with the functional group on the first carbon, or central and symmetrical in the case of the dialkyl ethers, were studied. Even so, increasing hydrocarbon chain length is frequently accompanied by greater divergence between calculated and measured water solubility values $[25,26]$.

Whole cell current cut-off responses were measured using hydrocarbons at saturated aqueous concentrations. This was done to ensure that each cut-off was independent of any particular endpoint (e.g., amnesia, unconsciousness, or immobility). Lack of receptor modulation at a saturated hydrocarbon concentration implies absent modulation at a lower pharmacologic concentration, including concentrations relevant to anesthetic endpoints. Anesthetic efficacy is in mammals is unknown for many, but not all, of the hydrocarbons tested. Primary alcohol anesthetic potency increases with increasing carbon chain length from methanol to dodecanol, after which further carbon additions do not produce anesthesia at all [27]. This anesthetic cut-off corresponds to the alcohol molar water solubility cut-off for $\mathrm{GABA}_{\mathrm{A}}$ receptors (Table 2). However, a general anesthesia cut-off effect has been reported to occur with $\mathrm{n}$-alkanes and dialkyl ethers having around 11-to-15 or more carbon atoms [28] and cycloalkanes having eight or more carbons atoms [29]. These molecules are far longer and have molar water solubility values far lower than occur with the $\mathrm{GABA}_{\mathrm{A}}$ receptor cut-off. Although observed anesthetic effects might be due to glycine receptor modulation, high affinity effects on one or more other anesthetic-sensitive receptors, or even 
systemic toxicity, it seems very possible that anesthetic effects could be the result of potent alcohol metabolites produced by oxidation of alkanes, cycloalkanes, and ethers by cytochrome P450 enzymes [30, 31]. Since the hydroxyl group confers greater molar water solubility, primary alcohols have receptor cut-offs at longer chain lengths than either alkanes or cycloalkanes or dialkyl ethers. These long-chain alcohol metabolites are also much more potent general anesthetics than their parent compounds [32], so even tiny quantities can have narcotic effects. Identifying simple parallels between in vitro receptor cut-offs and in vivo anesthetic cut-offs thus may be complicated for certain classes of organic compounds.

Channel studies were conducted using a reductionist biological system. However, in vitro electrophysiologic responses conducted at room temperature for relevant anesthetic-sensitive ion channels in oocytes seem to correlate with anesthetic potency in animals [33-35]. Likewise, the hydrocarbons studied in Table 1 administered in vivo would be expected to similarly modulate ion channels; in the case of drugs below the solubility cut-off, no in vivo modulation would be expected at all.

Finally, the molar water solubility hypothesis could offer practical applications to the development of new and novel inhaled anesthetic agents. Conventional volatile anesthetics bind promiscuously to a variety of cell proteins, but not all of these receptor interactions are essential to their ability to produce general anesthesia. For example, NMDA receptors contribute to immobilizing actions of inhaled anesthetics able to inhibit their function, but experimental inhaled anesthetics can still be immobilizers without producing NMDA receptor inhibition [36]. Since there is nearly a 10 -fold separation in the hydrocarbon molar water solubility cut-off effects between NMDA versus $\mathrm{GABA}_{\mathrm{A}}$ receptors, a volatile anesthetic might be modified to target calculated aqueous solubility values within this range to confer selectivity against higher cut-off NMDA receptors while preserving activity at lower cut-off $\mathrm{GABA}_{\mathrm{A}}$ receptors. With sufficient $\mathrm{GABA}_{\mathrm{A}}$ receptor potentiation and contributions of lower cut-off receptors, such an agent might retain immobilizing potency but lose adverse effects associated with the modulation of higher cut-off receptors. Consequently, molar water solubility could be key to identifying volatile anesthetics with new molecular mechanisms of action and improved pharmacodynamic profiles.

\section{Conclusions}

Anesthetic-sensitive ion channels and receptors all appear to exhibit allosteric cut-off effects associated with drug molar water solubility. These results support the Molar Water Solubility Hypothesis mechanism for non-specific protein interactions with drugs of varied sizes and shapes administered at relatively high aqueous phase concentrations, such as occurs with inhaled anesthetic agents. Low- affinity binding at allosteric sites may occur following successful displacement of water by a hydrocarbon molecule (or portion thereof). However, when a hydrocarbon has a molar water solubility below the allosteric cut-off for a channel, as likely determined by the dissociation constant for water at the allosteric site, that hydrocarbon cannot be delivered at a concentration sufficient to outcompete the water for binding site access. In addition to describing how anesthetics of various sizes and shapes may be able to modulate functions of different anesthetic-sensitive ion channels and receptors, the Molar Water Solubility Hypothesis and order of receptor cut-offs offers a unique tool for the development of new inhaled anesthetic agents. By changing substituents on molecules to decrease their molar water solubility, it may be possible to generate novel inhaled anesthetics that are selective against some of the ion channels or receptors normally modulated by conventional volatile anesthetics.

\section{Abbreviations \\ $G A B A_{A}$ : $y$-aminobutyric acid receptor type $A_{;} \mathrm{Na}_{\mathrm{V}} 1.2$ : Voltage-gated sodium channels type II; Nav1.4: Voltage-gated sodium channels type IV; \\ NMDA: N-methyl-d-aspartate; TREK-1: TWIK-related potassium channel type I; TRESK: TWIK-related spinal cord potassium channel}

\section{Funding}

This work was funded by the National Institutes of Health National Institutes of General Medical Sciences (Grant GM092821-02).

\section{Availability of data and materials}

The datasets used and analyzed during the current study are available from the corresponding author on reasonable request.

\section{Authors' contributions}

RJB: Conceived the idea, designed the experiments, assisted with some measurements, analyzed the data, and wrote the manuscript. TLP: Performed study measurements and reviewed the manuscript draft. Both authors read and approved the final manuscript.

\section{Ethics approval}

This project was conducted under Protocol \#19753 which was approved by the Institutional Animal Care and Use Committee of the University of California, Davis.

\section{Consent for publication}

Not applicable.

\section{Competing interests}

Aspects of this work are included in intellectual property filings and issued patents regarding the identification and use of new inhalation anesthetics and analgesics. Dr. Brosnan is the inventor of record, and patents are owned by the University of California. The University of California has licensed this intellectual property to Expanesthetics, Inc. (Davis, CA), and Dr. Brosnan is Chair of the Expanesthetics Scientific Advisory Board. Neither Dr. Brosnan nor Mr. Pham has received financial compensation from Expanesthetics, Inc., and neither owns equity in Expanesthetics, Inc.

\section{Publisher's Note}

Springer Nature remains neutral with regard to jurisdictional claims in published maps and institutional affiliations. 
Received: 13 June 2018 Accepted: 22 August 2018

Published online: 14 September 2018

\section{References}

1. Fisher E. Einfluss der Configuration auf die Wirkung der Enzyme. Ber Dtsch Chem Ges. 1894;27(3):2985-93.

2. Brosnan RJ, Steffey EP. Inhalation anesthetics. In: Riviere JE, Papich MG, editors. Veterinary Pharmacology and Therapeutics. 10th ed. Hoboken: Wiley; 2018. p. 216-46.

3. Steffey EP, Mama KR, Brosnan RJ. Inhalation anesthetics. In: Grimm KA, Lamont LA, Tranquilli WJ, Greene SA, Robertson SA, editors. Veterinary anesthesia and analgesia. 5th ed. Ames: Wiley; 2015. p. 237-331.

4. Franks NP, Lieb WR. Selective actions of volatile general anaesthetics at molecular and cellular levels. Br J Anaesth. 1993;71(1):65-76.

5. Bhattacharya AA, Curry S, Franks NP. Binding of the general anesthetics propofol and halothane to human serum albumin. High resolution crystal structures. J Biol Chem. 2000;275(49):38731-8.

6. Brosnan RJ, Pham TL. Hydrocarbon molar water solubility predicts NMDA vs. GABAA receptor modulation. BMC Pharmacol Toxicol. 2014;15:62.

7. Brosnan RJ, Pham TL. GABAA receptor modulation by phenyl ring compounds is associated with a water solubility cut-off value. Pharmacology. 2016;98(1-2):13-9.

8. Herold KF, Hemmings HC Jr. Sodium channels as targets for volatile anesthetics. Front Pharmacol. 2012;3:50.

9. Chae YJ, Zhang J, Au P, Sabbadini M, Xie GX, Yost CS. Discrete change in volatile anesthetic sensitivity in mice with inactivated tandem pore potassium ion channel TRESK. Anesthesiology. 2010;113(6):1326-37.

10. Heurteaux C, Guy N, Laigle C, Blondeau N, Duprat F, Mazzuca M, LangLazdunski L, Widmann C, Zanzouri M, Romey G, et al. TREK-1, a K+ channe involved in neuroprotection and general anesthesia. EMBO J. 2004;23(13): 2684-95.

11. Mihic SJ, McQuilkin SJ, Eger El 2nd, lonescu P, Harris RA. Potentiation of gamma-aminobutyric acid type a receptor-mediated chloride currents by novel halogenated compounds correlates with their abilities to induce general anesthesia. Mol Pharmacol. 1994;46(5):851-7.

12. Zhang Y, Laster MJ, Hara K, Harris RA, Eger El 2nd, Stabernack CR, Sonner JM. Glycine receptors mediate part of the immobility produced by inhaled anesthetics. Anesth Analg. 2003;96(1):97-101.

13. Horishita T, Harris RA. n-Alcohols inhibit voltage-gated Na+ channels expressed in Xenopus oocytes. J Pharmacol Exp Ther. 2008;326(1):270-7.

14. Peoples RW, Weight FF. Differential alcohol modulation of $G A B A_{A}$ and NMDA receptors. Neuroreport. 1999;10:97-101.

15. Franks NP, Lieb WR. Temperature dependence of the potency of volatile general anesthetics: implications for in vitro experiments. Anesthesiology. 1996;84(3):716-20.

16. Brannigan G, LeBard DN, Henin J, Eckenhoff RG, Klein ML. Multiple binding sites for the general anesthetic isoflurane identified in the nicotinic acetylcholine receptor transmembrane domain. Proc Natl Acad Sci U S A. 2010;107(32):14122-7.

17. Forman SA, Miller KW. Anesthetic sites and allosteric mechanisms of action on Cys-loop ligand-gated ion channels. Can J Anaesth. 2011;58(2):191-205.

18. Bondarenko V, Mowrey DD, Tillman TS, Seyoum E, Xu Y, Tang P. NMR structures of the human alpha7 nAChR transmembrane domain and associated anesthetic binding sites. Biochim Biophys Acta. 2014;1838(5):1389-95.

19. Brooks CL, Karplus M, Pettitt BM. Proteins: a theoretical perspective of dynamics, structure, and thermodynamics. New York: Wiley; 1988

20. Krimmer SG, Betz M, Heine A, Klebe G. Methyl, ethyl, propyl, butyl: futile but not for water, as the correlation of structure and thermodynamic signature shows in a congeneric series of thermolysin inhibitors. ChemMedChem. 2014;9(4):833-46

21. Brosnan R, Gong D, Cotten J, Keshavaprasad B, Yost CS, Eger El 2nd, Sonner $J$ M. Chirality in anesthesia II: stereoselective modulation of ion channel function by secondary alcohol enantiomers. Anesth Analg. 2006;103(1):86-91.

22. Borghese CM, Werner DF, Topf N, Baron NV, Henderson LA, Boehm SL 2nd, Blednov YA, Saad A, Dai S, Pearce RA, et al. An isoflurane- and alcoholinsensitive mutant GABA(A) receptor alpha(1) subunit with near-normal apparent affinity for GABA: characterization in heterologous systems and production of knockin mice. J Pharmacol Exp Ther. 2006;319(1):208-18.

23. Borghese CM, Xiong W, Oh SI, Ho A, Mihic SJ, Zhang L, Lovinger DM, Homanics GE, Eger El 2nd, Harris RA. Mutations M287L and Q266l in the glycine receptor alpha1 subunit change sensitivity to volatile anesthetics in oocytes and neurons, but not the minimal alveolar concentration in knockin mice. Anesthesiology. 2012;117(4):765-71.

24. Borghese CM, Blednov YA, Quan Y, lyer SV, Xiong W, Mihic SJ, Zhang L, Lovinger DM, Trudell JR, Homanics GE, et al. Characterization of two mutations, M287L and Q266l, in the alpha1 glycine receptor subunit that modify sensitivity to alcohols. J Pharmacol Exp Ther. 2012;340(2):304-16.

25. Coates M, Connell DW, Barron DM. Aqueous solubility and octan-1-ol-water partition coefficients of aliphatic hydrocarbons. Environ Sci Technol. 1985; 19(7):628-32.

26. Amidon GL, Yalkowsky SH, Leung S. Solubility of nonelectrolytes in polar solvents II: solubility of aliphatic alcohols in water. J Pharm Sci. 1974;63(12): 1858-66.

27. Alifimoff JK, Firestone LL, Miller KW. Anaesthetic potencies of primary alkanols: implications for the molecular dimensions of the anaesthetic site. Br J Pharmacol. 1989:96(1):9-16.

28. Jeppsson R. Parabolic relationship between lipophilicity and biological activity of aliphatic hydrocarbons, ethers and ketones after intravenous injections of emulsion formulations into mice. Acta Pharmacol Toxicol (Copenh). 1975;37(1):56-64

29. Fang Z, Sonner J, Laster MJ, lonescu P, Kandel L, Koblin DD, Eger El 2nd, Halsey MJ. Anesthetic and convulsant properties of aromatic compounds and cycloalkanes: implications for mechanisms of narcosis. Anesth Analg. 1996;83(5):1097-104

30. Pennec A, Jacobs CL, Opperman DJ, Smit MS. Revisiting cytochrome P450mediated Oxyfunctionalization of linear and cyclic alkanes. Adv Synth Catal. 2015:357(1):118-30.

31. Brady JF, Lee MJ, Li M, Ishizaki H, Yang CS. Diethyl ether as a substrate for acetone/ethanol-inducible cytochrome P-450 and as an inducer for cytochrome(s) P-450. Mol Pharmacol. 1988;33(2):148-54.

32. Eger El 2nd, Eisenkraft JB, Weiskopf RB. The Pharmacology of Inhaled Anesthetics. 2nd ed. San Antonio: Dannemiller Memorial Education Foundation; 2003

33. Zimmerman SA, Jones MV, Harrison NL. Potentiation of gammaaminobutyric acidA receptor $\mathrm{cl}$ - current correlates with in vivo anesthetic potency. J Pharmacol Exp Ther. 1994;270(3):987-91.

34. Rehberg B, Xiao YH, Duch DS. Central nervous system sodium channels are significantly suppressed at clinical concentrations of volatile anesthetics. Anesthesiology. 1996;84(5):1223-33. discussion 1227A

35. Eger El 2nd, Liao M, Laster MJ, Won A, Popovich J, Raines DE, Solt K, Dutton RC, Cobos FV 2nd, Sonner JM. Contrasting roles of the N-methyl-D-aspartate receptor in the production of immobilization by conventional and aromatic anesthetics. Anesth Analg. 2006;102(5):1397-406.

36. Brosnan RJ, Fukushima FB, Pham TL. Anesthetic synergy between two nalkanes. Vet Anaesth Analg. 2017:44(3):577-88.

Ready to submit your research? Choose BMC and benefit from:

- fast, convenient online submission

- thorough peer review by experienced researchers in your field

- rapid publication on acceptance

- support for research data, including large and complex data types

- gold Open Access which fosters wider collaboration and increased citations

- maximum visibility for your research: over $100 \mathrm{M}$ website views per year

At $\mathrm{BMC}$, research is always in progress.

Learn more biomedcentral.com/submission 